\title{
Avaliação e comparação do acúmulo de fósforo por biofilme formado sobre lâminas de vidro e de filme polimérico biodegradável (Ecovio ${ }^{\circledR}$ modificado)
}

\section{Evaluation and comparison of phosphorus accumulation by biofilm formed on glass slides and biodegradable polymer film (Ecovio ${ }^{\circledR}$ modified)}

\author{
Anna Cláudia Morashashi ${ }^{1}$; Tatiane Araújo de Jesus ${ }^{2}$; Derval dos Santos Rosa ${ }^{3}$; \\ Júlio Harada ${ }^{4}$; Denise de Campos Bicudo ${ }^{5}$
}

\begin{abstract}
'Aluna do Programa de Pós-graduação em Ciência e Tecnologia Ambiental, Universidade Federal do ABC, Santo André, São Paulo, Brasil. Orcid: http://orcid.org/0000-0003-1597-2841 E-mail: anna.morashashi@gmail.com

${ }^{2}$ Professora do Programa de Programa de Pós-graduação em Ciência e Tecnologia Ambiental, Universidade Federal do ABC, Santo André, São Paulo, Brasil. Orcid: http://orcid.org/0000-0002-5206-6584 E-mail: tatiane.jesus@ufabc.edu.br

${ }^{3}$ Professor do Programa de Programa de Pós-graduação em Ciência e Tecnologia Ambiental, Universidade Federal do ABC, Santo André, São Paulo, Brasil. Orcid: http://orcid.org/0000-0001-9470-0638 E-mail: derval.rosa@ufabc.edu.br

${ }^{4}$ Doutor em Nanociências e Materiais Avançados, Universidade Federal do ABC Santo André, São Paulo, Brasil. Orcid: http://orcid.org/0000-0001-9834-241X E-mail: harada.julio@terra.com.br
\end{abstract}

${ }^{5}$ Pesquisadora Científica, Núcleo de Ecologia do Instituto de Botânica de São Paulo, Secretaria do Meio Ambiente, São Paulo, São Paulo, Orcid: http://orcid.org/0000-0002-4248-3261 E-mail: denisecbicudo@gmail.com

RESUMO: A eutrofização é um dos principais problemas ambientais da atualidade e vem afetando diversos mananciais no Brasil e no mundo. O processo é caracterizado pelo aumento da biomassa dos produtores primários em decorrência das altas concentrações de nutrientes, em especial, do fósforo $(P)$, tendo como principais consequências: perda da biodiversidade e aumento dos custos do tratamento da água. Apesar das consequências indesejáveis da eutrofização, o $\mathrm{P}$ é um elemento químico essencial à produção de alimentos e suas fontes naturais estão se esgotando. Desse modo, o reaproveitamento do fósforo é de extrema importância para a manutenção da vida. Assim, o presente estudo teve como objetivo avaliar e comparar o acúmulo de fósforo em biofilme formado sobre lâminas de vidro e de filme polimérico biodegradável (Ecovio ${ }^{\circledR}$ modificado), com o intuito de desenvolver tecnologia mitigadora do processo de eutrofização e que permita o reaproveitamento do fósforo (suporte biodegradável). Para tanto, lâminas de vidro e do filme polimérico biodegradável $\left(14 \mathrm{~cm}^{2}\right)$ foram fixadas em estruturas flutuantes $(n=3)$ instaladas na subsuperfície de ambiente hipereutrófico (Lago das Garças), onde permaneceram por um período de 30 dias. Foram determinados os teores de fósforo total do biofilme e realizado o monitoramento de parâmetros de qualidade da água. $O$ acúmulo de fósforo sobre o filme polimérico biodegradável $\left(24,4 \mathrm{mg} \cdot \mathrm{g}^{-1} ; 698,8\right.$ $\left.\mathrm{mg} \cdot \mathrm{m}^{-2}\right)$ foi superior ao do vidro $\left(8,0 \mathrm{mg} \cdot \mathrm{g}^{-1} ; 169,1 \mathrm{mg} \cdot \mathrm{m}^{-2}\right)$ e as taxas de acúmulo de $P$ foram superiores aos valores disponíveis em literatura. Dessa forma, a tecnologia vem se mostrando promissora para a mitigação do processo de eutrofização e recuperação de fósforo.

Palavras-chave: Eutrofização; Perifíton; Sistema de Engenharia Ecológica.

ABSTRACT: Eutrophication is one of the main environmental problems of the present time and has been affecting several water sources in Brazil and in the world. The process is characterized by the increase of the biomass of the primary producers due to the high concentrations of nutrients, especially the phosphorus (P), having as main consequences: loss of biodiversity and increased costs for water treatment. Despite the undesirable consequences of eutrophication, $P$ is a chemical element essential to food production and its natural sources are depleting. In this way, the reuse of phosphorus is extremely important for the life maintenance. Thus, the aim of the present study was to evaluate and to compare the accumulation of phosphorus in biofilm formed on glass and biodegradable polymeric film (Ecovio ${ }^{\circledR}$ modified) in order to develop technology that mitigates the eutrophication process and allows the reuse of phosphorus (biodegradable support). For that, glass slides and biodegradable polymeric film $\left(14 \mathrm{~cm}^{2}\right)$ were fixed in floating structures $(n=3)$ installed in the subsurface of a hypertrophic environment (Garças Lake), where they remained for a period of 30 days. The total phosphorus content of the biofilm was determined and some water quality parameters were monitored. The accumulation of phosphorus on the biodegradable polymeric film (24.4 mg. $\left.\mathrm{g}^{-1} ; 698.8 \mathrm{mg} \cdot \mathrm{m}^{-2}\right)$ was superior to that of glass $\left(8.0 \mathrm{mg} \cdot \mathrm{g}^{-1} ; 169.1 \mathrm{mg} \cdot \mathrm{m}^{-2}\right)$ and that the accumulation rates of $P$ were higher than the values found in the literature. In this way, the technology has shown to be promising for the mitigation of the eutrophication process and $P$ recovery.

Keywords: Eutrophication; Periphyton; Ecological Engineering System.

DOI: $10.18554 /$ rbcti.v4i2.3696

\begin{tabular}{|l|l|l|l|l|l|l} 
Rev. Bras. Cien. Tec e Inov. & Uberaba, MG & v. 4 & n. 2 & p. 131-145 & jul./set. /2019 & ISSN 2359-4748
\end{tabular} 
INTRODUÇÃO

A água é um recurso essencial aos seres vivos, no entanto, em função do crescimento populacional, da urbanização, de seu intenso uso na indústria e agricultura e do acelerado aumento da poluição de rios e lagos, a água própria para consumo torna-se cada vez mais escassa (BAl et al., 2017). De acordo com o Relatório das Nações Unidas sobre Desenvolvimento dos Recursos Hídricos (ONU, 2016) a expectativa é de que em 2050 , cerca de 2,3 bilhões de pessoas estejam vivendo em áreas com grave restrição hídrica, ou seja, cerca de $25 \%$ da população mundial viverá em ambientes expostos a altos riscos associados à má qualidade da água.

No Brasil, os mananciais que abastecem os grandes centros urbanos estão sofrendo com a elevada densidade demográfica em função da sua grande demanda. Somado a isso, a situação se agrava pelo processo de deterioração da qualidade das águas (GALLI, 2010). Segundo a Agência Nacional de Águas (ANA, 2015), 21\% dos pontos analisados nas áreas urbanas do país apresentam o índice de qualidade de água classificados como sendo péssimo ou ruim.

Neste contexto a eutrofização destaca-se como sendo um dos principais processos responsáveis pela deterioração da qualidade da água. A eutrofização é caracterizada pelo aumento da produtividade da biomassa em decorrência do excesso de nutrientes presentes nas águas do ambiente aquático, e, por conseguinte, em seu desequilíbrio (WETZEL, 2001). O fenômeno pode ocorrer tanto naturalmente quanto artificialmente. Quando ocorre de forma natural o processo é lento e contínuo, e, por isso, muitas vezes é denominado de "envelhecimento" do corpo hídrico (ESTEVES; TUNDISI, 2011). Já o processo antrópico é caracterizado pelo dinamismo e velocidade elevada, em que ocorrem grandes modificações nas comunidades aquáticas, nos parâmetros limnológicos e no nível de produção do sistema, podendo ser considerada uma forma de poluição (ESTEVES; TUNDISI, 2011). O processo ganha destaque dentre as questões ambientais tendo em vista a projeção para 2050, onde o número de pessoas afetadas pelo excesso de nutrientes atingirá um terço da população mundial (ONU, 2016).

As principais implicações decorrentes da eutrofização são: aumento da biomassa de algas, proliferação de algas potencialmente tóxicas, alterações na biomassa e composição de espécies de macrófitas, aumento da frequência da mortandade de peixes, diminuição da biomassa de moluscos cultiváveis, redução da diversidade de espécies, redução da transparência da água, problemas de gosto e odor, aumento do custo do tratamento de água para abastecimento, depleção dos níveis de oxigênio dissolvido e redução do valor estético do corpo de água (GALLI, 2010).

Com vistas à contenção e redução do processo de eutrofização destaca-se o controle das concentrações de fósforo, uma vez que, para a realização da fotossíntese é necessário oito vezes mais átomos de nitrogênio do que de fósforo, tornando o elemento fósforo limitante ao processo (JOBGEN et al., 2004; FERRAGUT et al., 2009; SCHINDLER et al., 2016). Além disso, o nitrogênio apresenta maior disponibilidade e mobilidade no meio ambiente em comparação ao fósforo (PETZOLDT et al., 2006; TUNDISI; TUNDISI, 2008; ESTEVES; TUNDISI, 2011). As principais fontes de fósforo são: rochas, águas residuais domésticas e industriais, fertilizantes, pesticidas e detergentes, que, quando não incorporados ao produto final, geram resíduos com substanciais concentrações de fósforo, que acabam se tornando uma fonte deste elemento (GALLI, 2010). 
Se por um lado as altas concentrações de fósforo estão causando um problema para os corpos d' água, por outro, a escassez deste elemento está pondo em risco a produção de alimentos. De acordo com as projeções futuras, o fósforo se tornará escasso, uma vez que a demanda por alimentos tende a aumentar. Atualmente, a obtenção deste elemento se dá, predominantemente, pela extração do mineral das rochas e não pela reciclagem dos rejeitos orgânicos. Nesse sentido, se torna vital desenvolver maneiras para que o fósforo incorporado à matéria orgânica retorne ao ecossistema (NESET; CORDELL, 2011).

Existem diversas tecnologias que têm por finalidade controlar o fósforo de maneira a reduzir o nível trófico dos corpos hídricos, tais como: precipitação química, adsorção e sistemas bacterianos (JEPPESEN et al., 2012). Entretanto, essas técnicas geralmente demandam de insumos químicos, representam custos elevados e/ou produzem lodos com altas concentrações de metais pesados (MARONEZE, 2014). Além disso, o fósforo é um elemento lábil nos corpos d'água, uma vez que se acumula no sedimento e pode ser liberado para a coluna d'água em condições redutoras e manter o sistema eutrofizado por longo período.

Pesquisas vêm demonstrando o potencial do biofilme como tecnologia mitigadora do processo de eutrofização, como é o caso do estudo realizado por Jobgen et al. (2004) no qual placas de polipropileno $(33 \mathrm{~cm} \times 40 \mathrm{~cm})$ foram dispostas de forma submersa em ambiente mesotrófico na Alemanha com vistas à formação do biofilme e consequente remoção de fósforo. Os autores constataram que aproximadamente $100 \mathrm{mg} \mathrm{P} \mathrm{m}^{-2}$ foram removidos do lago juntamente com o biofilme formado sobre as placas, em um período de 4 meses de colonização.

Outro estudo que comprova a capacidade do biofilme na remoção de fósforo de sistema aquático eutrofizado foi o realizado por Pei et al. (2015), onde pedras de granito $(15 \times 8 \times 1 \mathrm{~cm})$ foram utilizadas como material suporte para o desenvolvimento de biofilme por um período de 48 dias em 4 lagos rasos temperados com diferentes estados tróficos na China. Para o lago Nanhu, hipereutrófico, a acumulação de fósforo total foi de $1290 \mathrm{mg}$ $\mathrm{m}^{-2}$. Para o lago Donghu, eutrófico, a acumulação de fósforo total foi de $1070 \mathrm{mg} \mathrm{m}^{-2}$. Para os lagos Niuchaohu e Liangzihu, mesotróficos, os valores de fósforo total acumulados foram, respectivamente, de $400 \mathrm{mg} \mathrm{m}^{-2}$ e $210 \mathrm{mg} \mathrm{m}^{-2}$. Além disso, os dados dos lagos em que o processo de eutrofização é mais avançado, Nanhu e Donghu, demonstraram rápida e abundante acumulação de fósforo disponível na coluna d'água (Nanhu: $22 \mathrm{mg} \mathrm{P} \mathrm{m}^{-2} \mathrm{~d}^{-1}$, Donghu: $13 \mathrm{mg} \mathrm{P} \mathrm{m}^{-2} \mathrm{~d}^{-1}$ ).

Já Lu et al. (2016) estudaram a influência de diferentes concentrações de fósforo para a formação de biofilme em diferentes compartimentos (água e sedimento). O estudo mostrou que as concentrações de fósforo da água diminuíram com a presença do biofilme, bem como, houve aumento do $\mathrm{pH}$, o que favoreceu a precipitação do fósforo e sais metálicos como o carbonato de cálcio. Dessa forma, o estudo sugere que o biofilme, além de acumular o fósforo dissolvido na água, também favorece a precipitação deste por aumentar o $\mathrm{pH}$ do meio.

Ressalta-se que o desenvolvimento do biofilme depende de alguns fatores, tais como: disponibilidade de nutrientes, temperatura, irradiação solar, velocidade e fluxo de água (DOODS, 2003; JOBGEN et al., 2004; OLIVEIRA et al., 2010; MAHDY et al., 2015), desse modo, esses fatores devem ser levado em consideração nos estudos que envolvem pesquisas com biofilme.

Nesse sentido a utilização do biofilme com vistas ao acúmulo de fósforo torna-se uma oportunidade como tecnologia verde de remediação de ambientes aquáticos 
eutrofizados, já que o biofilme é reconhecido por sua capacidade de remover nutrientes da coluna d'água (DODDS, 2003; CALIJURI; CUNHA, 2013; LU et al., 2016; HE et al., 2017).

Entretanto, apesar dos estudos citados demonstrarem que o biofilme tem potencial como tecnologia para a mitigação do processo de eutrofização, geralmente, costuma-se utilizar materiais não biodegradáveis como suporte para a formação do biofilme, o que exigiria etapa mecânica de remoção do biofilme para a recuperação do P. Desta forma, a utilização do filme polimérico biodegradável como material suporte para a formação do biofilme é uma inovação, já que, além do biofilme assimilar o fósforo dissolvido na água e, com isso, contribuir com a mitigação do processo de eutrofização, também possibilita a reciclagem do fósforo para a agricultura. Além disso, pelo material suporte ser biodegradável não há a necessidade de fazer a remoção mecânica do biofilme, trazendo assim maior praticidade e agilidade ao processo.

Tradicionalmente, os estudos de ecologia e composição química do biofilme utilizam lâminas de vidro como material suporte (ex. OLIVEIRA et al. 2010). Desse modo, este substrato foi utilizado para comparação no presente estudo.

Assim, o presente estudo teve por objetivo avaliar e comparar o acúmulo de fósforo em biofilme formado sobre lâminas de vidro e filme polimérico biodegradável (Ecovio ${ }^{\circledR}$ modificado) em ambiente hipereutrofizado (Lago das Garças, SP). Pretende-se, assim, contribuir com o desenvolvimento de tecnologia mitigadora do processo de eutrofização em ambientes lacustres e com o reaproveitamento do fósforo.

\section{MATERIAL E MÉTODOS}

\section{Área de Estudo}

O Lago das Garças está localizado no Parque Estadual das Fontes do Ipiranga (PEFI), situado a sudeste do município de São Paulo. O reservatório tem área superficial de $88.156 \mathrm{~m}^{2}$, com profundidade média de $2,1 \mathrm{~m}$, podendo chegar a $4,7 \mathrm{~m}$ de profundidade máxima (BICUDO et al., 2002). O clima da área é classificado como tropical de altitude, apresentando precipitação média anual de $1.368 \mathrm{~mm}$, temperatura média de $15^{\circ} \mathrm{C}$ no mês mais frio e, nos meses mais quentes, a variação é de $21,4^{\circ} \mathrm{C}$ a $21,6^{\circ} \mathrm{C}$ (SANTOS; FUNARI, 2002). Atualmente, o lago recebe efluentes da Estação de Tratamento de Esgotos da Fundação Parque Zoológico de São Paulo, a qual opera a nível secundário, ou seja, sem etapa específica de remoção de nutrientes.

\section{Delineamento Experimental}

Três estruturas flutuantes (Figura 1) contendo lâminas $(3,00 \mathrm{~cm} \times 8,00 \mathrm{~cm})$ dos diferentes materiais (filme polimérico biodegradável e vidro) foram dispostas na região pelágica do Lago das Garças (Figura 2) a uma profundidade de aproximadamente $25 \mathrm{~cm}$ da superfície da água. As estruturas flutuantes eram constituídas de: poita (Figura 1a), um aparato para dar sustentação às lâminas (Figura 1b) e uma estrutura para fixar as lâminas (Figura 1c), além de permitir que as lâminas se mantivessem equidistantes em relação à superfície. As lâminas foram colocadas no lago em 16 de janeiro de 2018 e permaneceram até 15 de fevereiro de 2018, perfazendo um período de 30 dias. Em cada estrutura foram fixadas 6 lâminas, sendo que 3 eram de vidro e 3 do filme polimérico 
biodegradável, perfazendo um total de 15 lâminas.

Figura 1: Aparato completo para fixação das lâminas.

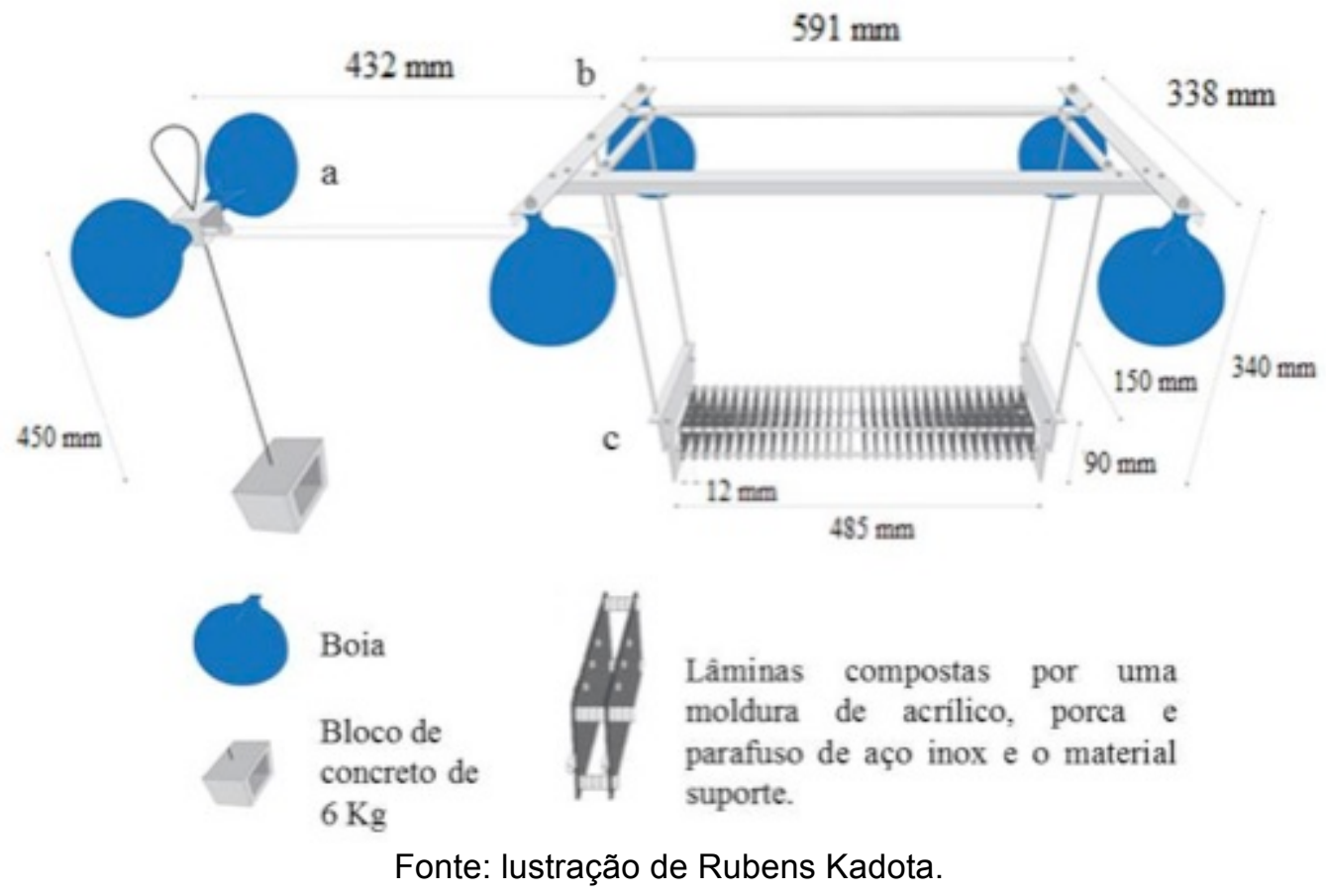

Figura 2: Mapa batimétrico do Lago das Garças com destaque para o local onde o experimento foi instalado.

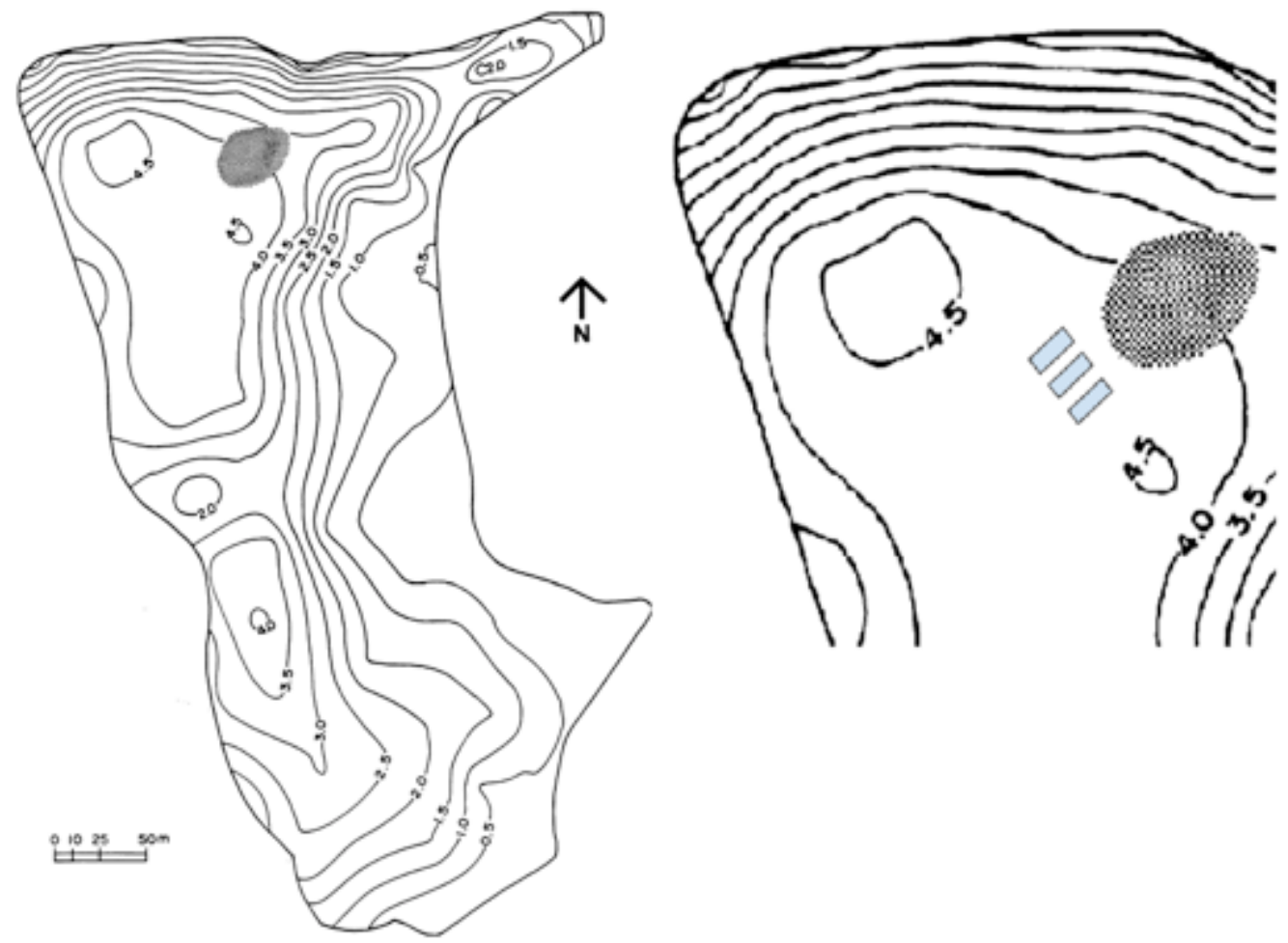

Fonte: Modificado de Bicudo et al., 2007 
Em relação aos materiais suporte, o vidro foi testado para fins de comparação, já que é rotineiramente utilizado em estudos de ecologia aquática. Já em relação ao filme polimérico biodegradável, trata-se do Ecovio ${ }^{\circledR}$ modificado, denominado aqui por "A7". O Ecovio $^{\circledR}$ é o nome comercial dado para a blenda de Polibutirato adipato-co-tereftalato (PBAT) e poli (ácido lático) (PLA), que é biodegradável e é produzido pela empresa BASF S.A. (BASF, 2010). O Ecovio ${ }^{\circledR}$ modificado foi desenvolvido por Harada (2008) e possui em sua composição: $92 \%$ de Ecovio ${ }^{\circledR}, 4 \%$ de composto orgânico, $2 \%$ de sílica e $2 \%$ de negro de fumo.

\section{Dados climáticos}

As médias diárias de temperatura do ar, irradiação solar e dados pluviométricos foram obtidos da Estação Meteorológica do Parque Cientec, que dista cerca de $300 \mathrm{~m}$ do local de estudo.

\section{Monitoramento}

Foram realizadas, mensalmente, coletas de amostras de água do Lago das Garças, as quais foram analisadas no laboratório do Instituto de Botânica de São Paulo. Já as amostras do biofilme foram analisadas nos Laboratórios de Caracterização de Matrizes Ambientais e de Análises Ambientais da Universidade Federal do ABC, Santo André.

As análises e os métodos que foram empregados estão descritos na Tabela 1. As determinações analíticas foram realizadas em triplicatas, a fim de assegurar a confiabilidade dos resultados. Para as análises colorimétricas, foram analisados brancos analíticos e de padrões de concentração conhecida para elaboração da curva de calibração do espectrofotômetro.

Tabela 1: Métodos empregados para as análises das amostras.

\begin{tabular}{|c|c|c|c|c|}
\hline $\begin{array}{c}\text { Parâmetro de } \\
\text { análise }\end{array}$ & Unidade & Matriz & Metodologia & Referência \\
\hline Temperatura & ${ }^{\circ} \mathrm{C}$ & Água & $\begin{array}{c}\text { Sonda multiparamétrica da marca Horiba, } \\
\text { modelo U50 }\end{array}$ & - \\
\hline $\begin{array}{l}\text { Transparência } \\
\text { da áqua }\end{array}$ & $\mathrm{cm}$ & Água & Disco de Secchi & - \\
\hline $\mathrm{pH}$ & $\mathrm{UpH}$ & Água & $\begin{array}{l}\text { Sonda multiparamétrica da marca Horiba, } \\
\text { modelo U50 }\end{array}$ & - \\
\hline $\begin{array}{l}\text { Condutividade } \\
\text { elétrica }\end{array}$ & $\mu S \mathrm{~cm}^{-1}$ & Água & $\begin{array}{c}\text { Sonda multiparamétrica da marca Horiba, } \\
\text { modelo U50 }\end{array}$ & - \\
\hline Clorofila-a & $\mu g L^{-1}$ & Água & Extração com etanol e espectrofotometria & Utermöhl (1958) \\
\hline $\begin{array}{l}\text { Oxigênio } \\
\text { Dissolvido }\end{array}$ & $\mathrm{mg} \mathrm{L}^{-1}$ & Água & Winkler modificado por Azida & $\begin{array}{l}\text { Golterman et al. } \\
\qquad(1978)\end{array}$ \\
\hline Fósforo Total & $\mu g L^{-1}$ & Água & Espectrofotômetro & Valderrama (1981) \\
\hline $\begin{array}{l}\text { Nitrogênio } \\
\text { Total }\end{array}$ & $\mu g L^{-1}$ & Água & Espectrofotômetro & Valderrama (1981) \\
\hline Fósforo Total & $\mu g L^{-1}$ & Biofilme & $\begin{array}{c}\text { Método } 4500 \text { - Digestão Ácido clorídrico } \\
\text { e Colorimetria }\end{array}$ & APHA (2012) \\
\hline
\end{tabular}


O Índice de Estado Trófico (IET) foi calculado seguindo a metodologia proposta por Carlson (1977) e modificada por Lamparelli (2004) que é empregada pela Cetesb (Companhia Ambiental do Estado de São Paulo) e não leva em consideração os valores de transparência da coluna d'água.

\section{RESULTADOS E DISCUSSÃO}

O estudo é referente ao período de janeiro de 2018, quando as lâminas foram instaladas no lago, até fevereiro de 2018, perfazendo 30 dias de experimento. Assim, para as análises dos resultados também foram avaliadas as variáveis climatológicas e limnológicas do mês em que a estrutura foi instalada, ou seja, no mês anterior à coleta dos biofilmes.

\section{Variáveis climáticas}

Em janeiro a temperatura do ar variou de $16,8^{\circ} \mathrm{C}$ a $32,4^{\circ} \mathrm{C}$, com média de $22,4^{\circ} \mathrm{C}$. Já em fevereiro, a temperatura do ar variou de $16,7^{\circ} \mathrm{C}$ a $33,9^{\circ} \mathrm{C}$, com média $21,5^{\circ} \mathrm{C}$. Em relação à precipitação, no mês de janeiro foram registrados 26 eventos e em fevereiro, apenas 15 eventos. Em janeiro a precipitação total foi de 177,9 mm e em fevereiro 62,5 $\mathrm{mm}$. Tais valores estão abaixo da média histórica, de 219,8 e 207,0, respectivamente, segundo a série temporal de 69 anos da Estação Meteorológica do Parque Cientec. A Figura 3 apresenta as médias diárias para a temperatura do ar e índice pluviométrico para o período de estudo. Além disso, a seta vermelha indica o dia em que ocorreu a coleta dos biofilmes.

Figura 3: Variação das médias diárias da temperatura do ar ( ${ }^{\circ} \mathrm{C}$ ) (linha contínua) e precipitação $(\mathrm{mm})$ (colunas) para os meses de janeiro de 2018 a fevereiro de 2018. A seta vermelha indica o dia da coleta dos biofilmes.

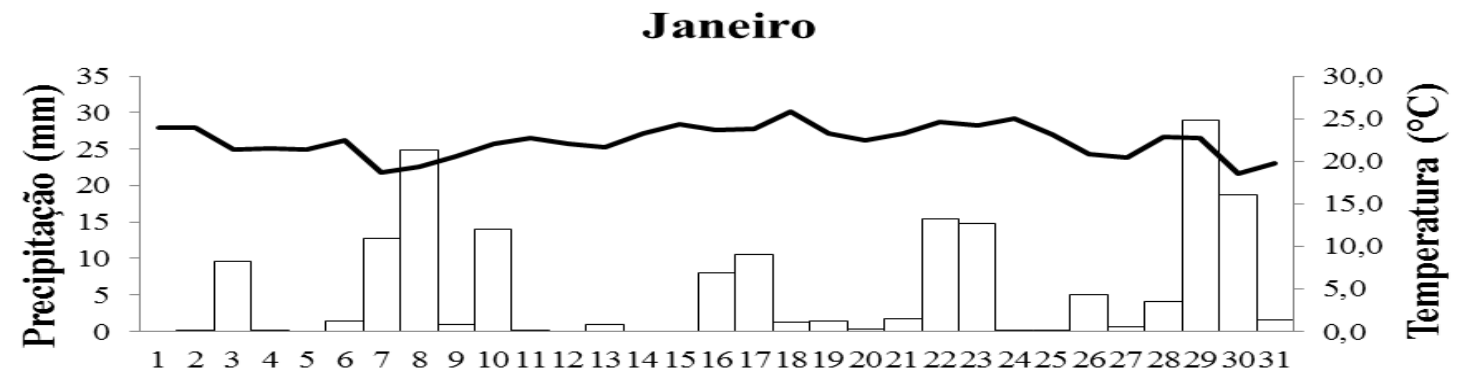

Dias

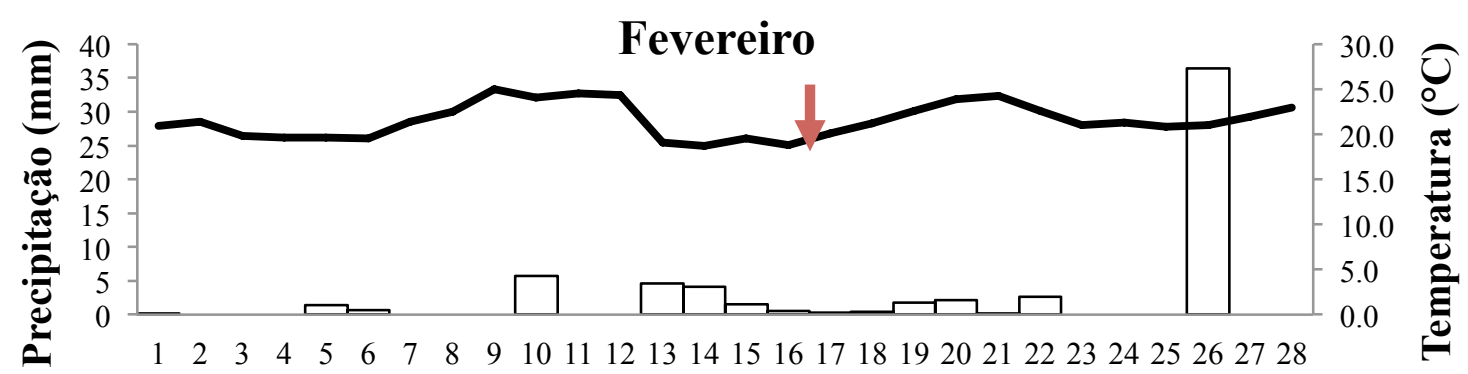

Dias 
Com relação à irradiação solar, o mês de janeiro apresentou média mensal de $17,14 \pm 5,8 \mathrm{MJ} \mathrm{m}^{-2}$ e fevereiro, média de 16,92 $\pm 5,3 \mathrm{MJ} \mathrm{m}^{-2}$. Já a média anual da

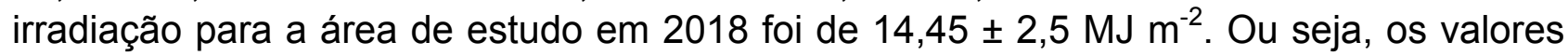
de irradiação no período de estudo foram superiores à média anual.

\section{Variáveis limnológicas}

A Tabela 2 apresenta o resumo das variáveis abióticas e do Índice de Estado Trófico (IET) do Lago das Garças para o período de estudo.

Tabela 2: Variáveis limnológicas para os meses de janeiro e fevereiro de 2018 e seus respectivos valores padrões de qualidade de águas doces classe 1 , segundo a Resolução CONAMA n $357 / 2005$.

\begin{tabular}{lccc}
\hline \multicolumn{1}{c}{ Variáveis abióticas } & Janeiro de 2018 & Fevereiro de 2018 & Valores Padrões \\
\hline Temperatura $\left({ }^{\circ} \mathbf{C}\right)$ & 22,73 & 23,93 & - \\
Transparência $(\mathbf{m})$ & 0,60 & 0,61 & - \\
pH & 6,00 & 8,04 & $6-9$ \\
Condutividade elétrica $\left(\boldsymbol{\mu S ~ ~ c m ^ { - 1 }}\right)$ & 248,0 & 264,0 & - \\
Clorofila-a $\left(\boldsymbol{\mu g ~ ~ ^ { - 1 } )}\right.$ & 100,69 & 89,71 & 10 \\
Oxigênio dissolvido $\left(\mathbf{m g ~ L}^{-1}\right)$ & 5,38 & 9,69 & 6 \\
Fósforo total $\left(\boldsymbol{\mu \mathbf { g ~ L } ^ { - 1 } )}\right.$ & 118,45 & 131,66 & 20 \\
Nitrogênio total $\left(\boldsymbol{\mu \mathbf { g ~ L } ^ { - 1 } )}\right.$ & 1355,7 & 1286,1 & 1270 \\
IET & 70,4 & 70,4 & - \\
\hline
\end{tabular}

As temperaturas nos dois meses estão acima do valor médio esperado para o local e época do ano que estaria entre $21,4^{\circ} \mathrm{C}$ a $21,6^{\circ} \mathrm{C}$ (SANTOS; FUNARI, 2002). Temperaturas mais altas aceleram o crescimento de algas, plantas e cianobactérias (CALLISTO et al., 2014). Tal fato pode ter favorecido o metabolismo do biofilme.

Com relação à transparência da água, não houve variação entre os meses estudados e os valores são semelhantes aos obtidos por Bicudo et al. (2007) e Oliveira et al. (2010) no mesmo ambiente, onde os autores também registraram cerca de 0,6 $\mathrm{m}$ para a transparência da água.

De acordo com o artigo $3^{\circ}$ do Decreto Estadual n 10.755/77 (SÃO PAULO, 1977) que dispõe sobre o enquadramento dos corpos de água, o Lago das Garças se enquadra como Classe 1 por estar dentro de uma Unidade de Conservação, logo, deveria atender aos padrões de qualidade para esta classe, conforme estabelecido na Resolução CONAMA 357/2005 (BRASIL, 2005). No entanto, conforme observado na Tabela 2 os resultados de todas as variáveis que constam na legislação foram superiores aos esperados para a sua classificação, exceto o $\mathrm{pH}$.

Os valores de $\mathrm{pH}$ estão dentro do intervalo padrão, entretanto, houve grande variação entre os dois meses estudados. A condutividade elétrica apresentou valores elevados e pequena variação entre os meses. Os valores de clorofila-a variaram de 89,71 $\mu \mathrm{g} \mathrm{L} \mathrm{L}^{-1}$ a $100,69 \mu \mathrm{g} \mathrm{L}^{-1}$, o que representa cerca de 10 vezes os valores padrões estabelecidos na legislação. No entanto, esses valores são inferiores aos valores obtidos anteriormente para o mesmo ambiente, de $771 \mu^{-1} \mathrm{~L}^{-1}$ (BICUDO et al., 2007).

Apenas o oxigênio dissolvido do mês de fevereiro atendeu aos valores padrões, no entanto, o valor obtido para o mês de janeiro está muito próximo ao estipulado. As concentrações de ambos os nutrientes, fósforo e nitrogênio, foram superiores aos valores 
padrões. Destaca-se que o fósforo apresentou concentrações cerca de 6 vezes superiores aos valores padrões.

O valores obtidos para o IET foram superiores a 67, o que classifica o Lago das Garças como hipereutrófico de acordo com CETESB (2013).

\section{Composição do biofilme}

A Figura 4 apresenta os gráficos da concentração de fósforo total no biofilme formado em diferentes materiais suporte para o período de estudo. Em ambas as concentrações o biofilme formado no material A7 apresenta maior acúmulo de fósforo em relação ao vidro 24,41 $\mathrm{mg} \mathrm{g}^{-1}$ e $8,02 \mathrm{mg} \mathrm{g}^{-1} ; 698,81 \mathrm{mg} \mathrm{m}^{-2}$ e $169,05 \mathrm{mg} \mathrm{m}^{-2}$, respectivamente.

Figura 4. (a) Concentrações de fósforo total por massa seca $\left(\mathrm{mg} \mathrm{g}^{-1}\right)$ e (b) por área ( $\mathrm{mg}$ $\mathrm{m}^{-2}$ ) ao longo do período de estudo para os biofilmes formados sobre os diferentes materiais suportes.

(a)

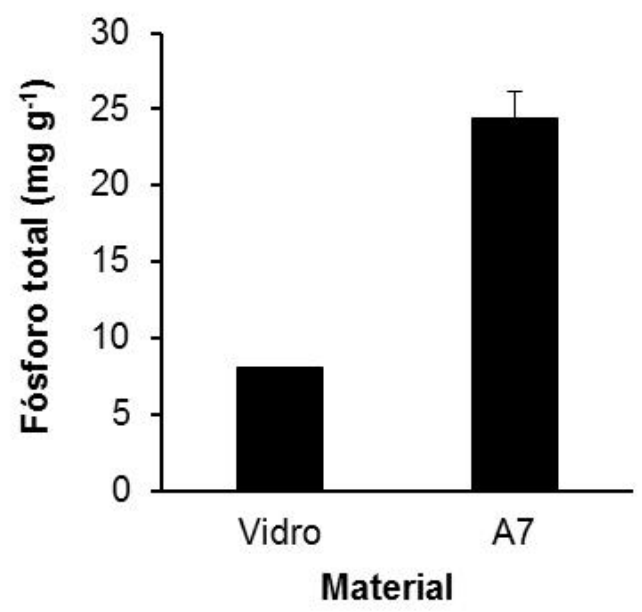

(b)

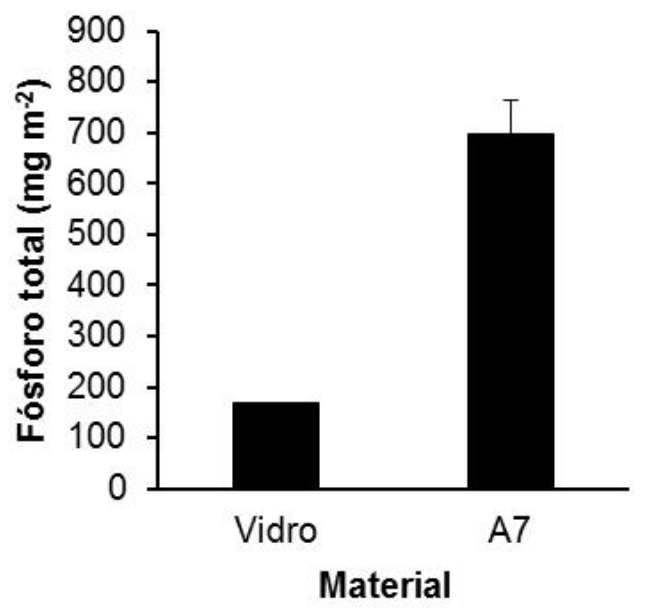

As variáveis climáticas, tais como: temperatura, irradiação solar e precipitação podem influenciar o desenvolvimento do biofilme em substrato artificial (DOODS, 2003; JOBGEN et al., 2004; OLIVEIRA et al., 2010; MAHDY et al., 2015). No período em que sucedeu o experimento, as temperaturas do ar estavam na média esperada para a região e época do ano. Já a precipitação ficou abaixo da média para o local, enquanto a radiação solar foi superior à média. Assim, todas as variáveis climáticas foram favoráveis para o desenvolvimento do biofilme, considerando os níveis de precipitação que não apresentaram eventos de chuva forte que pudessem causar a perda da biomassa do biofilme (SANTOS; FERRAGUT, 2013).

As variáveis abióticas da coluna d'água que apresentam relação com o desenvolvimento do biofilme são: temperatura, transparência da coluna d'água e a disponibilidade de nutrientes, pois elas influenciam na atividade metabólica dos organismos que compõe o biofilme (DODDS, 2003; LIBORIUSSEN; JEPPESEN, 2006; OLIVEIRA et al., 2010; MARTINS; FERNANDES, 2011; BORDUQUI; FERRAGUT, 2012; SOUZA; FERRAGUT, 2013).

Em estudo anterior realizado no Lago das Garças, os autores avaliaram os fatores 
relacionados às variações sazonais da biomassa do biofilme formado sobre lâminas de vidro e dos nutrientes presentes no Lago das Garças (OLIVEIRA et al., 2010). Os autores obtiveram valores médios de transparência da água de $0,4 \mathrm{~m}$ e de temperatura da água de $21,4{ }^{\circ} \mathrm{C}$, valores menores em comparação aos obtidos no presente estudo. Em relação aos nutrientes as concentrações de fósforo total $\left(208,4 \mu \mathrm{g} \mathrm{L}^{-1}\right)$ e nitrogênio total $(2498 \mu \mathrm{g}$ $\mathrm{L}^{-1}$ ) foram quase duas vezes maiores de que as obtidas no presente estudo. Para 0 acúmulo de fósforo por massa seca livre de cinzas (MSLC) de biofilme os valores foram menores em aproximadamente 0,75 P MSLC\%, frente aos aqui obtidos (1,2 P.MSLC\% para o vidro e 3,7 P.MSLC\% para o "A7").

Em estudo realizado por Pei et al. (2015), os lagos Nanhu e Donghu apresentaram concentrações de fósforo total de $790 \mu \mathrm{g} \mathrm{L}^{-1}$ e $230 \mu \mathrm{g} \mathrm{L}^{-1}$ e nitrogênio total de $8170 \mu \mathrm{g} \mathrm{L}^{-1}$ e $1360 \mu \mathrm{g} \mathrm{L}^{-1}$, respectivamente. Tais valores são bastante superiores aos obtidos no presente estudo. Como esperado, as concentrações de fósforo no biofilme também foram superiores às obtidas neste estudo. Para o lago de Nanhu o biofilme acumulou $1290 \mathrm{mg}$ $\mathrm{m}^{-2}$ de PT e para o lago Donghu o acúmulo de PT no biofilme foi de $1070 \mathrm{mg} \mathrm{m}^{-2}$.

As taxas de acumulação de fósforo obtidas neste e em outros estudos encontramse na Tabela 3. Pode-se notar que o valor da taxa acumulação de fósforo para o material suporte $A 7$ foi bem superior às de outros estudos e apenas similar ao Lago Nanhu. Ressalta-se que este material apresenta em sua composição matéria orgânica, sílica e negro de fumo, que podem ter contribuído para a formação e desenvolvimento do biofilme por ter fornecido substrato para tal. Para o vidro o valor foi apenas inferior ao estudo realizado por Pei et al. (2015) em que foram utilizados pedras de granito como material suporte. Ressalta-se que no estudo de Pei et al. (2015) as concentrações de fósforo e nitrogênio para ambos os lagos foram superiores às do Lago das Garças. Comparando os resultados com o estudo realizado por Balle \& Jesus (2014), realizado no mesmo ambiente e na mesma época do ano (chuvoso) com uso de lâminas de PET (Politereftalato de etileno) como material suporte a taxa de acumulação do presente estudo foi superior. Destaca-se que apesar de ambos os experimentos terem sido executados no mesmo local e no mesmo período do ano, no presente estudo houve diferença na estrutura utilizada para dispor as lâminas que permitiram que os biofilmes ficassem sempre dispostos nos mesmo locais e nas mesmas condições.

Tabela 3: Taxa de acumulação de fósforo obtida em outros estudos de biofilme ( ${ }^{1} \mathrm{PEI}$ et al. 2015; ' JOGBEN, 2004; ${ }^{3}$ BALLE; JESUS, 2014).

\begin{tabular}{|c|c|c|c|}
\hline Local & Material Suporte & $\begin{array}{l}\text { Acumulação de } \\
\text { Fósforo total por área } \\
\left(\mathrm{mg} \mathrm{m}^{-2}\right)\end{array}$ & $\begin{array}{l}\text { Taxa de Acumulação } \\
\text { de Fósforo } \\
\left(\mathrm{mg} \mathrm{m}^{-2} \mathrm{~d}^{-1}\right)\end{array}$ \\
\hline Lago Nanhu (China) ${ }^{1}$ & Pedras de Granito & 1290 & 22 \\
\hline Lago Donghu (China) ${ }^{1}$ & Pedras de Granito & 1070 & 13 \\
\hline Lago Fuhlinger (Alemanha) ${ }^{2}$ & Polipropileno & 100 & 0,8 \\
\hline Lago das Garças (Brasil) ${ }^{3}$ & Vidro & 36,9 & 0,84 \\
\hline Lago das Garças (Brasil) ${ }^{3}$ & PET & 43,0 & 0,98 \\
\hline Lago das Garças (Brasil) & Vidro & 169,1 & 5,6 \\
\hline Lago das Garças (Brasil) & A7 & 698,8 & 23,3 \\
\hline
\end{tabular}


CONCLUSÕES

As condições climáticas e limnológicas do período em que o experimento foi realizado foram favoráveis ao desenvolvimento do biofilme, uma vez que houve altos índices de radiação, elevada temperatura tanto da água quanto do ar, disponibilidade de nutrientes, transparência na coluna d'água e não houve eventos de precipitação com grandes acúmulos.

Os valores das taxas acumulação de fósforo obtidos para o biofilme formado sobre o filme polimérico biodegradável "A7" $\left(23,3 \mathrm{mg} \mathrm{m}^{-2} \mathrm{~d}^{-1}\right)$ foram superiores aos obtidos para o vidro $\left(5,6 \mathrm{mg} \mathrm{m}^{-2} \mathrm{~d}^{-1}\right)$, bem como àqueles obtidos em outros estudos. Isso se deu, possivelmente, pela composição do material "A7", bem como, pela forma como os materiais suportes foram dispostos no lago. Desse modo, a tecnologia se mostra promissora para a mitigação do processo de eutrofização e do reaproveitamento de fósforo.

\section{AGRADECIMENTOS}

Os Autores agradecem à Estação Meteorológica do Instituto Astronômico e Geofísico da Universidade de São Paulo pela disponibilização dos dados climáticos, bem como ao Instituto de Botânica pelo apoio institucional e aos estagiários pela ajuda em campo e no laboratório.

\section{REFERÊNCIAS}

AGÊNCIA NACIONAL DE ÁGUAS. Superintendência de Planejamento de Recursos Hídricos. Conjuntura dos recursos hídricos: informe 2015. Brasília. p-88. Disponível em: http://www3.snirh.gov.br/portal/snirh/centrais-de-conteudos/conjuntura-dos-recursoshidricos/conjuntura_informe_2015.pdf/view Acesso em: 23 abr. 2019.

\section{APHA, AWWA, WEF. Standard methods for the examination of water and}

wastewater. American Public Health Association, 22ª ed., Washington. 2012.

BAI, M.; ZHOU, S.; ZHAO, M.; YU, J. Water use efficiency improvement against a backdrop of expanding city agglomeration in developing countries- A case study on industrial and agricultural water use in the Bohai Bay region of China. Water, v. 9, n 2, p 122. 2017. Disponível em:

https://www.researchgate.net/publication/313284408_Water_Use_Efficiency_Improvement against_a_Backdrop_of_Expanding_City_Agglomeration_in_Developing_CountriesA_Case_Study_on_Industrial_and_Agricultural_Water_Use_in_the_Bohai_Bay_Region_of _China Ácesso em: 23 abr.2019.

BALLE, M. G.; JESUS, T. A. Avaliação da taxa de acumulação de fósforo por biofilme perifítico com vistas ao desenvolvimento de biotecnologia de remediação ambiental. $X$ ENCONTRO NACIONAL DE ÁGUAS URBANAS. São Paulo: Associação Brasileira de Recursos Hídricos. São Paulo p. 4. 2014. Disponível em:

http://eventos.abrh.org.br/xenau/apresentacoes/4/17_09_11h23_murilo.pdf Acesso em: 23 abr. 2019. 
BASF. 2010. Bioplastic, Biomaterial. Industrial Biotechnology, v. 6, n. 6, p. 303-313.

BICUDO, C.E.M.; CARMO, C.F.; BICUDO, D.C.; HENRY, R.; PIÃO, A.C.S.; SANTOS, C.M. \& LOPES, M.R.M. Morfologia e morfometria de três reservatórios do PEFI. In: BICUDO, D, C.; FORTI, M.C.; BICUDO, C.E.M. Parque Estadual das Fontes do Ipiranga: unidade de conservação ameaçada pela urbanização de São Paulo. São Paulo: Editora Secretaria do Meio Ambiente do Estado de São Paulo. p. 141-158. 2002. Disponível em:

https://www.researchgate.net/publication/43655154_Parque_estadual_das_fontes_do_Ipir anga_unidade_de_conservacao_que_resiste_a_urbanizacao_de_Sao_Paūo Acesso em: $23 \mathrm{abr} .2019$.

BICUDO, D. C.; FONSECA, B. M.; BINI, L. M.; CROSSETTI, L. O.; BICUDO, C. E. M.; JESUS, T. A. Undesirable side-effects of water hyacinth control in a shallow tropical reservoir. Freshwater Biology, v. 52, n. 6, p. 1120-1133. 2007. Disponível em: https://repositorio.ucb.br/jspui/bitstream/123456789/7564/1/Undesirable\%20sideeffects\%20of\%20water\%20hyacinth\%20control\%20in\%20a\%20shallow\%20tropical\%20re servoir.pdf Acesso em: 23 abr. 2019.

BORDUQUI, M.; FERRAGUT, C. Factors determining periphytic algae succession in a tropical hypereutrophic reservoir. Hydrobiologia, v. 683, n. 1, p.109-122. 2012. Disponível em: https://pubag.nal.usda.gov/catalog/569762 Acesso em: 23 abr. 2019.

BRASIL. Resolução n 357, de 17 de março de 2005. Resolução Conama n 357/2005. Brasil: Dou, 18 mar. 2005. n. 053, p. 58-63. Disponível em:

http://www2.mma.gov.br/port/conama/res/res05/res35705.pdf Acesso em: 23 abr. 2019.

CALIJURI, M. C; CUNHA, D. G. F. Engenharia ambiental: conceitos, tecnologia e gestão. Rio de Janeiro, p. 832. 2013.

CALLISTO, M.; MOLOZZI, J.; BARBOSA, J. L. E. Eutrophication of lakes. In: ANSARI, A.; GILL, S. S. Eutrophication: causes, consequences and control. Nova York. p. 55-71. 2014.

CARLSON, R.E. A trophic state index for lakes. Limnology and Oceanography, v. 22, n. 2, p. 361-369. 1977.

CETESB. 2013. Águas Interiores. Índices de qualidade das águas: Índice do Estado Trófico. São Paulo. Disponível em: http://aguasinteriores.cetesb.sp.gov.br/wpcontent/uploads/sites/32/2013/11/04.pdf. Acesso em: 4 jul. 2017.

DODDS, W. K. 2003. The role of periphyton in phosphorus retention in shallow freshwater aquatic systems. Journal of Phycology, v. 39, n. 5, p. 840-849. Disponível em: https://www.researchgate.net/publication/227619026_The_Role_of_Periphyton_in_Phosp horus_Retention_in_Shallow_Freshwater_Aquatic_Systems Acesso em: 23 abr. 2019.

SÃO PAULO (Estado). Decreto $\mathrm{n}^{\circ}$ 10755, de 22 de novembro de 1977. Disponível em: https://www.al.sp.gov.br/norma/153028 Acesso em: 23 abr. 2019. 
ESTEVES, F. A.; TUNDISI, T. M. Fundamentos de limnologia. Rio de Janeiro: Interciência. p. 826. 2011.

FERRAGUT, C.; BICUDO, D. C. Efeito de diferentes níveis de enriquecimento por fósforo sobre a estrutura da comunidade perifítica em represa oligotrófica tropical (São Paulo, Brasil). Revista Brasileira de Botânica, v. 32, n. 3, p.571-585. 2009. Disponível em: http://www.scielo.br/pdf/rbb/v32n3/a15v32n3 Acesso em: 23 abr. 2019.

GALLI, C. S.; ABE, D. S. Disponibilidade, poluição e eutrofização das águas. In: BICUDO, C. E. M.; TUNDISI, J. G.; SCHEUENSTUHL, M. C. B. (org). Águas do Brasil: Análise Estratégica. São Paulo: Instituto de Botânica. 2010. p. 165-174.

GOLTERMAN H.L.; CLYMO R.S.; OHMSTAD M.A.M. Methods for physical and chemical analysis of freshwaters. Blackwell Scientific Publications, Oxford. International Biological Program. 1978.

HARADA, J. Novos filmes poliméricos biodegradáveis contendo compostos orgânicos e Sílicas para aplicações na área agrícola. 2018. Tese (Doutorado em Nanociência) - Pós-Graduação em Nanociência e Materiais Avançados, Universidade Federal do ABC, Santo André. p. 161. 2018.

HE, H.; LUO, X.; JIN, H.; GU, J.; JEPPESEN, E.; LIU, Z.; LI, K. Effects of Exposed Artificial Substrate on the Competition between Phytoplankton and Benthic Algae: Implications for Shallow Lake Restoration. Water, v. 9, n. 1, p. 24-33. 2017. Disponível em: https://pdfs.semanticscholar.org/a651/177dc02281fa443161ee2dd128126fee3fa1.pdf Acesso em: 23 abr. 2019.

JEPPESEN, E.; SONDERGAARD, M.; LAURIDSEN, T. L.; DAVIDSON, T. A.; LIU, Z.; MAZZEO, N.; TROCHINE, C.; OZKAN, K.; JENSEN, H. S.; TROLLE, D.; STARLING, F.; LAZZARO, X.; JOHANSSON, L. S.; BJERRING, R.; LIBORIUSSEN, L.; LARSEN, S. E.; LANDKILDEHUS, F.; EGEMOSE, S.; MEERHOFF, M. Biomanipulation as a Restoration Tool to Combat Eutrophication. Advances In Ecological Research, p. 411-488. 2012. Disponível em: http://www.documentation.ird.fr/hor/fdi:010060887 Acesso em: 23 abr. 2019.

JOBGEN, A.; PALM, A.; MELKONIAN, M. Phosphorus removal from eutrophic lakes using periphyton on submerged artificial substrata. Hydrobiologia, 528, 1-3, p.123-142. 2004. Disponível em: Acesso em: 23 abr. 2019.

LAMPARELLI, M. C. Graus de trofia em corpos d'água do estado de São Paulo: avaliação dos métodos de monitoramento. 2004. Tese (Doutorado em Ecologia) Universidade de São Paulo, São Paulo. 235 p. 2004. Disponível em: https://www.teses.usp.br/teses/disponiveis/41/41134/tde-20032006075813/publico/TeseLamparelli2004.pdf Acesso em: 23 abr. 2019.

LIBORIUSSEN, L.; JEPPESEN, E. Structure, biomass, production and depth distribution of periphyton on artificial substratum in shallow lakes with contrasting nutrient 
concentrations. Freshwater Biology, v. 51, n. 1, p. 95-109. 2006. Disponível em: https://www.researchgate.net/publication/230021772_Structure_biomass_production_and _depth_distribution_of_periphyton_on_artificial_substratum_in_shallow_lakes_with_contra sting_nutrient_concentrations Acesso em: 23 abr. 2019.

LU, H.; SHAO, H.; LI, J.; WU, Y. Periphytic biofilm: A buffer for phosphorus precipitation and release between sediments and water. Chemosphere, v. 144, p. 2058-2064. 2016. Disponível em: https://www.ncbi.nlm.nih.gov/pubmed/26583287 Acesso em: 23 abr. 2019.

MAHDY, A.; HILT, S.; FILIZ, N.; BEKLIOGLU, M.; HEJZLAR, J.; OZKUNDAKCI, D.; PAPASTERGIADOU, E.; SCHARFENBERGER, U.; SORF, M.; STEFANIDIS, K.; TUVIKENE, L.; ZINGEL, P.; SONDERGAARD, M.; JEPPESEN, E.; ADRIAN, R. Effects of water temperature on summer periphyton biomass in shallow lakes: a pan-European mesocosm experiment. Aquatic Sciences, v.77, n. 3, p. 499-510. 2015. Disponível em: https://www.researchgate.net/publication/277403509_Effects_of_water_temperature_on_s ummer_periphyton_biomass_in_shallow_lakes_a_pan-European_mesocosm_experiment Acesso em: 23 abr. 2019.

MARONEZE, M.M.; ZEPKA, L. Q.; VIEIRA, J. G.; QUEIROZ, M. I.; LOPES, E. J. A. Tecnologia de remoção de fósforo: gerenciamento do elemento em resíduos industriais.

Revista Ambiente \& Água, Taubaté, v.9, n. 3, p. 445-458. 2014. DOI:

http://dx.doi.org/10.4136/ambi-agua.1403

Disponível em: http://www.scielo.br/scielo.php?pid=S1980-

993X2014000300008\&script=sci_abstract\&tlng=en Acesso em: 23 abr. 2019.

MARTINS, F. C. O.; FERNANDES, V. O. Biomassa e composição elementar (C, N e P) da comunidade perifítica em diferentes gradientes fluviais tropicais (alto rio Santa Maria da Vitória, Espírito Santo, Brasil). Brazilian Journal Of Aquatic Science And Technology, v. 15, n. 1, p. 11-18. 2011. Disponível em:

https://siaiap32.univali.br/seer/index.php/bjast/article/view/1702 Acesso em: 23 abr. 2019.

NESET, T. S. S; CORDELL, D. Global phosphorus scarcity: identifying synergies for a sustainable future. Journal Of The Science Of Food And Agriculture, London, v. 92, n. 1, p. 2-6. Disponível em: https://www.ncbi.nlm.nih.gov/pubmed/21969145 Acesso em: 23 abr. 2019.

OLIVEIRA, D. E.; FERRAGUT, C.; BICUDO, D. C. Relationships between environmental factors, periphyton biomass and nutrient content in Garças Reservoir, a hypereutrophic tropical reservoir in southeastern Brazil. Lakes \& Reservoirs: Research \& Management, v.15, n. 2, p. 129-137. 2010. DOI: https://doi.org/10.1111/j.1440-1770.2010.00428.x Disponível em: https://onlinelibrary.wiley.com/doi/abs/10.1111/j.1440-1770.2010.00428.x Acesso em: 23 abr. 2019.

ORGANIZAÇÃO DAS NAÇÕES UNIDAS (ONU). Union Nation Water. World Water Assessment Programme. Relatório Mundial das Nações Unidas sobre Desenvolvimento dos Recurcos Hídricos 2016: Água e Emprego, Fatos e números. Collombella, Perugia, Itália, p. 12. 2016. Disponível em: http://www.unesco.org/new/pt/brasilia/naturalsciences/environment/wwdr/ Acesso em: 23 abr. 2019. 
PEI, G.; WANG, Q.; LIU, G. The role of periphyton in phosphorus retention in shallow lakes with different trophic status, China. Aquatic Botany, v. 125, p. 17-22. 2015.

PETZOLDT, T; UHLMANN, D. Nitrogen emissions into freshwater ecosystems: is there a need for nitrate elimination in all wastewater treatment plants. Acta Hydrochimica Et Hydrobiologica, v.34, n. 4, p.305-324. 2006. Disponível em:

https://onlinelibrary.wiley.com/doi/abs/10.1002/aheh.200500638 Acesso em: 23 abr. 2019.

SANTOS, P. M.; FUNARI, F. L. Clima local. In: BICUDO, D C; FORTI, M C; BICUDO, C M. Parque Estadual das Fontes do Ipiranga (PEFI): unidade de conservação que resiste a urbanização de São Paulo. São Paulo: Secretaria do Meio Ambiente do Estado de São Paulo. 2002.Cap. 2. p. 29-48.

SANTOS, T. R.; FERRAGUT, C. The successional phases of a periphytic algal community in a shallow tropical reservoir during the dry and rainy season. Limnetica, Madrid, v. 2, n. 32, p. 337-352. 2013. Disponível em:

http://www.limnetica.com/Limnetica/Limne32/L32b337_Periphytic_algal_community_tropic al_reservoir.pdf Acesso em: 23 abr. 2019.

SCHINDLER, D. W.; CARPENTER, S. R.; CHAPRA, S. C.; HECKY, R. E.; ORIHEL, D. M. Reducing Phosphorous to Curb Lake Eutrophication is a Success. Environmental

Science \& Technology, v. 50, p. 8923- 8929. 2016. Disponível em:

https://pubs.acs.org/doi/abs/10.1021/acs.est.6b02204 Acesso em: 23 abr. 2019.

SOUZA, M. L.; FERRAGUT, C. Influence of substratum surface roughness on periphytic algal community structure in a shallow tropical reservoir. Acta Limnologica Brasiliensia, v. 24, n. 4, p. 397-407. 2013.

TUNDISI, J. G.; TUNDISI, T. M. Limnologia. São Paulo: Oficina de Textos. p.631. 2008.

UTERMOHL, H. Zur vervollkommnung der quantitative Phytoplankton-methodik.

Mitteilungen Internationale Vereinigung fur Theoretische und Angewandte Limnologie, v. 9. p. 1-38. 1958.

VALDERRAMA, G. C. The simultaneous analysis of total nitrogen and total phosphorus in natural waters. Marine Chemistry, v. 10. p. 109 - 112. 1981. Disponível em:

https://www.researchgate.net/publication/223643214_The_simultaneous_analysis_of_total _nitrogen_and_total_phosphorus_in_natural_waters Acesso em: 23 abr. 2019.

WETZEL, R. G. The phosphorus cycle. In: WETZEL, R. G. Limnology: lake and river ecosystems. San Diego: Elsevier. p. 239-286. 2001.

Recebido em: 22/04/2019

Aprovado em: 03/06/2019 